\title{
Gravimetric and Spectrophotometric Determination of Surface Wax Content in Maize Kernels
}

\author{
Fatih Kahriman (Corresponding author) \\ Faculty of Agriculture, Department of Field Crops, \\ Canakkale Onsekiz Mart University, PO box 17100, Turkey \\ E-mail: fkahriman@hotmail.com \\ Iskender Onac \\ Turkish Ministry of Agriculture and Forestry, \\ Tunceli Directorate of Provincial Agriculture and Forestry, Turkey \\ E-mail: ionac@gmail.com \\ Baris Alaca \\ Georg-August-Universitat Gottingen Wilhelmsplatz 1 \\ PO box 37073 Gottingen, Germany \\ E-mail: bar.alaca@yahoo.com \\ Cem Omer Egesel \\ Faculty of Agriculture, Department of Agricultural Biotechnology, \\ Canakkale Onsekiz Mart University, PO box 17100, Turkey \\ E-mail: cegesel@comu.edu.tr
}

The research is financed by The Scientific and Technological Research Council of Turkey (TUBITAK Project Number: 2150867). (Sponsoring information)

\begin{abstract}
There are several methods available to determine wax content in maize kernel. These methods are based on gravimetric, spectrophotometric, and chromatographic analyses. This study aims to determine the surface wax content on maize kernel with different reference methods and develop NIR (Near Infrared Reflectance Spectroscopy) calibration models based on those reference methods. In this study, samples from 250 different maize genotypes were used. Surface wax content in the samples was determined by gravimetric and UV-Spectrophotometric methods. The results of each reference method were used to develop NIR prediction models for surface wax content in kernel samples. Our results suggest that there is a medium-level correlation $(\mathrm{r}=0.708)$ between the data obtained from spectrophotometric and gravimetric methods. Also, significant differences were observed between the wax content obtained from reference methods. It has been found that the NIR calibration model $(\mathrm{RMSE}=4.381, \mathrm{R} 2=0.143, \mathrm{r}=0,378$, $\mathrm{RPD}=1.08$ ) based on the gravimetric method had lower estimation power than the NIR calibration model $(\mathrm{RMSEC}=7.257, \mathrm{R} 2=0.221, \mathrm{r}=0.471, \mathrm{RPD}=1.34)$ based on the UV spectroscopic method.
\end{abstract}

Keywords: Near Infrared Spectroscopy, Biochemical test, Zea mays, Regression

DOI: $10.7176 /$ JSTR/5-9-11

\section{Introduction}

The surface wax secreted by epidermal cells is considered a part of the self-protection mechanisms in plants. Being a building element of the cuticle layer, wax has been associated with resistance against different biotic and abiotic stress factors in maize (Bianchi et al., 1984, Kunst et al, 2009, Sampietro et al., 2009). Common pathogens of maize crop such as Aspergillus and Fusarium have been studied in relation with wax layer on the seed and protective effect of wax has been reported by several authors (Sampietro et al., 2009, Guo et al., 1995, Bragdon, 1951, Tubajika and Damann, 2001). In addition to acting as a physical barrier, it is also considered to have a chemical based repelling effect against pathogens (Russin et al., 1997).

85 | P a g e

www.iiste.org 
Waxy layer also provides a better tolerance against drought (Dar et al., 2017). Global climate changes are not a story of the future anymore. Agricultural areas around the globe are under the effect of increasing temperatures, where new varieties are needed to cope with the warmer environments (Hatfield et al., 2018). Accordingly, breeding programs ought to pay much more attention to drought tolerance from now on. Any plant trait that would contribute to drought tolerance would be an asset for the breeders to go after. In this respect, maize genotypes synthesizing a thicker wax layer may attract the breeders in the future much more than they do today.

The wax content in maize may also have some other uses that we do not care much in today's world. Production of sustainable green packaging materials (Sharma et al., 2018) and industrial feedstocks, use as a substitute for current petrochemicals (Vanhercke et al., 2018) are some of such possibilities. Coupling with the opportunities offered by new biotechnological tools, we may have plants produce the raw materials, such as wax, in much higher quantities for this kind of industrial uses.

All of these studies indicate that surface wax, a marginal component of the maize plant, seems to offer potential for several agronomic and industrial uses. In that case, the scientists will be in the need of credible analysis methods that can provide reliable data on wax content of plant tissues. It is important to quantify the amount of wax in the seed coat in a precise, fast and economical way.

There are different methods available to determine kernel wax in maize, and these methods basically rely on gravimetric, spectrophotometric, and chromatographic approaches. In gravimetric methods, the samples are treated with an organic solvent, such as chloroform, to dissolve the wax layer, and the quantitation is achieved after volatilizing (Russin et al., 1997). Determination of wax with the spectrophotometric, more specifically colorimetric, method relies on a chemical reaction between wax and acidic $\mathrm{K}_{2} \mathrm{Cr}_{2} \mathrm{O}_{7}$ reagent (Bragdon, 1951). At the end of this reaction, samples with different wax content are supposed to yield visible differences in color. Chromatographic method, despite its better level of accuracy, is the least preferred one among the reference methods to analyze wax content. The best chromatographic way for determining the wax content and its components is the combination of gas chromatography and mass spectroscopy (Regert et al., 2005). In this method, the volatile substances within the wax are directly analyzed with GC-MS (Grob et al., 1995), while nonvolatile components require a derivatization first, and then a chromatographic analysis (Asperger et al., 2001). How the results from these different methods compare to each other is an issue of concern, but limited data are available on this matter. Ebercon et al. (1997) compared gravimetric and colorimetric methods in analyzing waxes of sorghum leaves. They noted that gravimetric method took much greater (as much as 10-fold) time and required a wider variety of samples than colorimetric method. The results, however, showed a good degree of correlation $(\mathrm{r}=0.984)$, suggesting that one can replace gravimetric analysis with colorimetric one. In general, the reference methods used to determine wax content are time consuming and require the use of expensive and harmful chemicals. Researchers could definitely use a cheaper, faster, and safer alternative in wax analyses. Near Infrared Reflectance (NIR) spectroscopy seems to have the potential to offer all of these advantages.

NIR spectroscopy has become more common and functional in industrial and scientific studies. International standardization institutes, such as AOAC, AACC, ICC, have already published some standards to hearten the application of near-infrared spectroscopy technique for determination of the biochemical contents of food and feed samples (Osborne, 2000). There is lots of research on the determination of biochemical components in maize with NIR spectroscopy. Estimation the levels of many different major and minor biochemical components in maize by means of NIR have been studied (Baye et al., 2006, Egesel and Kahriman, 2012, Kahriman et al., 2015, Egesel et al., 2015, Egesel et al., 2016, Kahriman et al., 2017). However, to our knowledge, there is no report on scientific literature about the development of NIR calibration models for predicting surface wax content in maize kernel. Also, effect of reference methods used has not been investigated on prediction performance of NIR calibration for surface wax content.

From this point of view, the objectives of this study were i) to compare the gravimetric and colorimetric analysis methods for surface wax quantification in maize kernels, ii) to develop NIR calibration models, and iii) to compare NIR prediction models developed based on gravimetric and colorimetric data and to examine the possibility of NIR instruments for analyzing the surface wax content in maize kernel.

\section{Materials and Methods}

\subsection{Maize samples}

In this study, samples from 250 different maize genotypes were used including 30 registered maize cultivars, 120 local maize populations, and 100 genotypes from our maize breeding studies. About a hundred gram kernel samples from each genotype was equally divided for chemical analyses and NIR spectra acquisition.

86 I P a g e

www.iiste.org 


\subsection{Gravimetric determination of surface wax content}

We utilized a gravimetric method to quantify kernel wax as described by Russin et al (1997). For this purpose, the weight of an empty glass tube was recorded. Then, 50 kernels were treated with $100 \mathrm{~mL}$ chloroform for 1 minute in this glass tube. After that, kernels were taken out and chloroform was evaporated with a rotary evaporator (Hahn Shin Scientific, Korea) at 30-40 ${ }^{\circ} \mathrm{C}$. Final weight of the tube was determined with a precision scale. The weight of the residual wax was calculated using the beginning and final weights of the tube.

\subsection{Colorimetric determination of surface wax content}

We also utilized a colorimetric analysis on the same set of genotypes following the method described by Ebercon et al (1997). This method was based on the color change produced by a chemical reaction of the wax with an acid (K2Cr2O7). Twenty grams of pulverized potassium dichromate was mixed with $40 \mathrm{~mL}$ deionized water to prepare the reagent. Onto this, $1 \mathrm{~L} 95 \%$ sulfuric acid was added, mixed strongly and heated till the solution turned clear. Five $\mathrm{mL}$ reagent was added into the tubes from the gravimetric analysis that contained the wax residues. The tubes were kept for 30 minutes in a boiling water bath. After cooling, $12 \mathrm{~mL}$ deionized water was added to each tube and waited for color development. Next, optical density was recorded at $590 \mathrm{~nm}$ for the samples. Wax standard curve was prepared using carbowax-3000 (Polyethylene Glycol-3000, Sigma-Aldrich) chemical. Standards were weighed into different test tubes in a range of 0 to $40 \mathrm{mg}$ and the same analytical process as explained above was applied to the standard samples. The standards obtained were linear $(Y=0.0269 x+0.0012, R 2=0.999)$ through the concentrations prepared.

2.4 Development of NIR calibration models for surface wax content

Prediction models for the determination of surface wax content were developed and externally validated. Half of the starting seed samples for each genotype were milled with a laboratory mill (Fritsch pulverizette 14, Germany) with a $0.5 \mathrm{~mm}$ sieve and spectral data collected from the milled samples (Figure 1a). These data were combined into spectrum files in jdx format by using Unity software (Unity Scientific, USA). The spectral data along with the data from reference analyses were transferred to Unscrambler X software (Camo Software, Norway) to develop NIR calibration models. The spectra files were subjected to the first derivative standard normal variate (SNV) transformations prior to model development (Figure 1b). The segment and gap values were taken as 5 and 3, respectively. NIR models have been developed based on Partial Least Squares Regression (PLSR). In the NIR estimation models, wax content values from the reference analyses were assigned as dependent variables, while the transformed spectra between 1200 and $2400 \mathrm{~nm}$ were defined as independent variables. Randomly selected 200 samples were used for the development of prediction models. The calibration models were evaluated according to RMSEC (The square root of the average of the error squares of the calibration), SEE (Standard error of calibration), r (Correlation coefficient), and R2 (Coefficient of determination) values. For validation of the models, 50 samples, independent from the calibration set, were used; and the robustness of the models was tested based on RMSEP (The square root of the average error squares), SEP (Standard error of prediction) and RPD (Performance to deviation ratio) values. Evaluation of calibration parameters were calculated according to the following equations:

$$
\begin{aligned}
& \text { RMSEP }=\sqrt{\frac{\sum(\text { Ypred }- \text { Yref })^{2}}{n}} \\
& \text { Bias }=\text { Ypred }-\bar{Y} r e f \\
& S E E=\sqrt{\frac{n}{n-1}\left(\text { RMSEP }^{2}-\text { Bias }^{2}\right)} \\
& R P D=\frac{S T D_{\text {ref }}}{S E_{\text {pred }}}
\end{aligned}
$$

where; RMSEP, the square of the average of the estimated squares; Ypred, calculated value; Yref, value obtained by standard analyzes; $n$, number of observations; Bias, the average difference between estimated and standardized analyzes; SEE, the standard error of the predicted values in the calibration set; STDref, standard deviation of reference analyzes, and SEpred, standard error of prediction values. 
a)

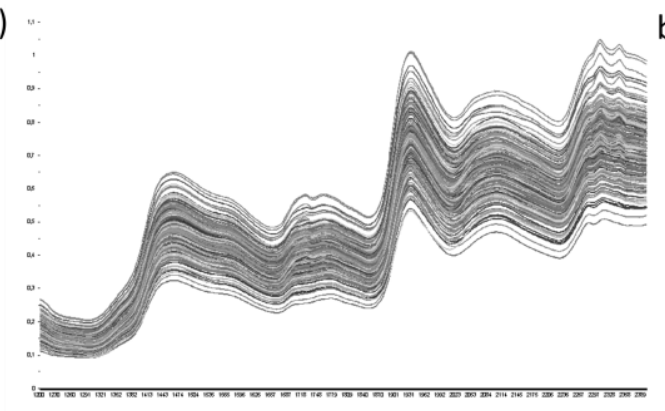

b)

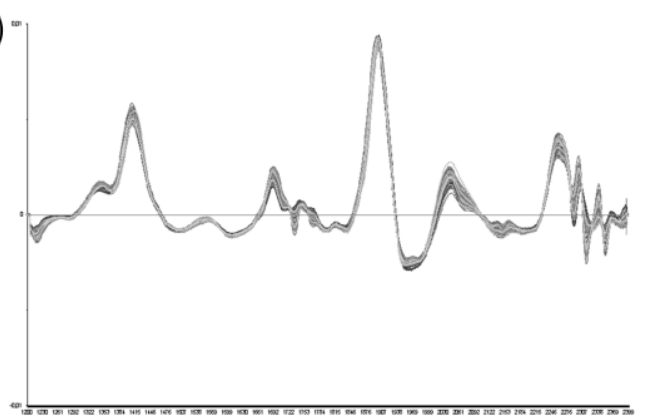

Fig. 1 Raw (a) and transformed (b) spectra obtained from flour samples by NIR instrument.

\section{Results and discussion}

\subsection{The results of reference methods}

Descriptive statistics for the wax content from the gravimetric and spectrophotometric methods used in this study were presented in Table 1 . The general mean of the samples with the gravimetric method was $5.45 \mathrm{mg}$, while the mean of the spectrophotometric method was $13.27 \mathrm{mg}$. The results showed that the variation of the wax content was significantly higher when analyzed with the spectrophotometric method as compared to the results from the gravimetric method (Table 1). A statistically significant difference $(\mathrm{p}<0.001)$ was found between the wax values obtained by different methods from the kernel samples (Figure 2a). It was also found that there was a moderate relationships $(\mathrm{R} 2=0.609 ; \mathrm{r}=0.708$ ) between wax contents obtained by gravimetric and spectrophotometric determinations (Figure 2b). Ebercon et al. (1997) quantified the surface wax from sorghum leaves by means of spectrophotometric and gravimetric methods, and reported a very high correlation between the results from these two methods. The fact that we determined a merely moderate correlation between the two methods could be attributed to two reasons: First, during the isolation of wax from the outer layers of the kernels, some other substances that are soluble in chloroform could be possibly involved in the solution, in different amounts changing from genotype to genotype. Earlier studies emphasized the effect of genotypes on the variation of wax content Ebercon et al., 1997, Sharma et al., 2018). The set of genotypes used in this study possessed a high level of genetic variation thereby increasing the chances of having such a misleading effect due to chloroformsoluble substances other than wax. As a matter of fact, $70.8 \%$ correlation coefficient value for 250 genotypes suggests that the results obtained from the different methods were quite similar (the data points located near the regression line) for some genotypes (Figure 2b). Second, the methods utilized different measurements. Although a high precision scale $(0.0000)$ is used in gravimetric method, incalculable errors may result in significant deviations during weighing operation. On the other hand, the chemical reagent used in the spectrophotometric method may react with substances other than wax, which had dissolved in the solvent (chloroform). These other substances may occur in varying amounts among the genotypes, and this would distort the precision and accuracy of wax quantification. Obtaining excessively higher wax values in our study from the spectrophotometric method, compared to the gravimetric method, may be attributed to this factor (Figure 2a). Similarly, Ebercon et al. (1997) reported higher values from the spectrophotometric method. Apparently, the differences between these reference analysis methods of wax content need to be studied in more detailed.

Table 1. Descriptive statistics for wax analysis methods.

\begin{tabular}{|l|c|c|c|c|c|}
\hline Analysis Method & $\mathrm{n}$ & Mean & Minimum & Maximum & STD \\
\hline Gravimetric method & 250 & 5,45 & 0,00 & 28,00 & 4,70 \\
\hline Spectrophotometric Method & 250 & 13,27 & 0,04 & 44,02 & 7,92 \\
\hline
\end{tabular}

\subsection{Evaluation of the developed NIR calibration models}

Descriptive statistics for the wax contents of the samples used in the NIR calibration and validation sets were presented in Table 2. In both calibration and external validation sets, average wax values were significantly higher with spectrophotometric method than gravimetric method (13.57 vs 5.46 and 12.06 vs 5.40, respectively). Range of the values in the calibration set was broader (0.04-44.00 mg) with the spectrophotometric method as opposed to $0.00-28.0 \mathrm{mg}$ of gravimetric method. The wax values obtained by gravimetric and spectrophotometric methods in the external validation set are included in the limit values of the calibration set (Table 2). 

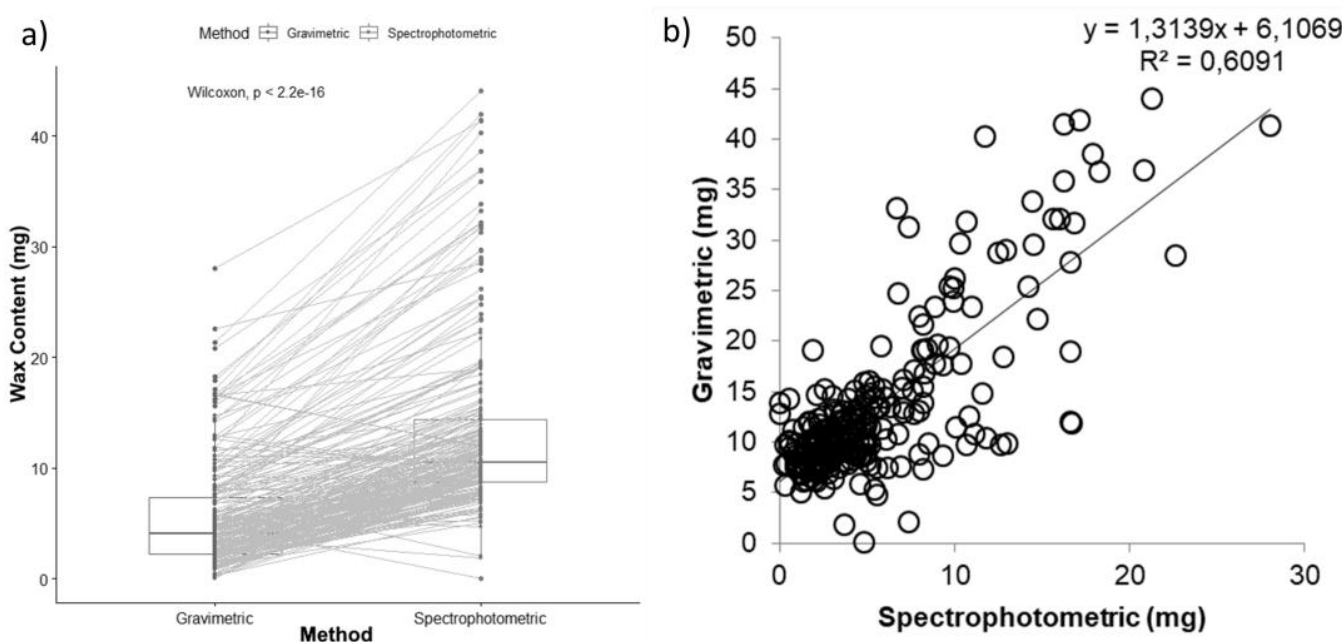

Fig 2 Paired box plot (a) and correlation plot (b) for wax content between reference methods.

Table 2. Descriptive statistics for the wax content in the calibration and validation sets.

\begin{tabular}{|l|c|c|c|c|}
\hline & \multicolumn{2}{|c|}{ Calibration Set } & \multicolumn{2}{c|}{ External Validation Set } \\
\hline & Gravimetric & UV-Spectroscopy & Gravimetric & UV-Spectroscopy \\
\hline N & 200 & 200 & 50 & 50 \\
\hline Mean & 5.46 & 13.57 & 5.40 & 12.06 \\
\hline Min & 0.00 & 0.04 & 0.30 & 1.89 \\
\hline Max & 28.0 & 44.02 & 22.6 & 35.03 \\
\hline STD & 4.75 & 8.248 & 4.63 & 6.47 \\
\hline
\end{tabular}

The evaluation results of NIR calibration models for wax content were presented in Table 3 and Figure 3. RMSEC and SEC values were found to be lower in the gravimetric method than in the UVSpectroscopic method, whereas $\mathrm{R}^{2}, \mathrm{r}$ and RPD values of the model formed by the UV-spectroscopic method were higher than those in the gravimetric method. It is noteworthy that the results obtained by the two methods are close to each other based on the results of external validation. General evaluations of these parameters suggest that NIR prediction model obtained by the spectrophotometric method had higher robustness than that of the gravimetric method.

Table 3. Evaluation parameters for the NIR estimation model for wax contents.

\begin{tabular}{|l|c|c|c|c|}
\hline & \multicolumn{2}{|c|}{ Calibration Set } & \multicolumn{2}{c|}{ External Validation Set } \\
\hline & Gravimetric & UV-Spectroscopy & Gravimetric & UV-Spectroscopy \\
\hline RMSE & 4.381 & 7.257 & 4.468 & 4.442 \\
\hline SE & 4.392 & 7.276 & 4.509 & 4.482 \\
\hline $\mathrm{R}^{2}$ & 0.143 & 0.221 & 0.067 & 0.060 \\
\hline $\mathrm{r}$ & 0.378 & 0.471 & 0.260 & 0.271 \\
\hline RPD & 1.08 & 1.34 & 1.03 & 1.33 \\
\hline
\end{tabular}

Scientific literature lacks reports on the determination of the wax content of maize with NIR spectroscopy. In fact, wax content is difficult to estimate with NIR technique when compared with other biochemical components, such as oil, protein etc. Prediction of surface wax content with NIR spectroscopy did not yield satisfactory results in our study. This result could be attributed to several reasons. First of all, the NIR spectroscopy instrument used in this study can only receive spectrum from bulk samples. In addition, samples have to be milled in order to reduce undesirable variations in spectral data, such as noise and baseline shift. In fact, earlier studies yielded unsuccessful results in determining 
the biochemical content of kernels when calibration models were developed based on the spectra taken on intact bulk seeds (Prieto et al., 2017). In our study, the surface wax content was analyzed using intact seeds, while the spectral data were collected on milled samples. These instrumental limitations had certainly an adverse effect on prediction performances of the NIR calibration models. It is remarkable that the predictive calibration model generated by the UV-spectrophotometric reference method has a higher R2 value than the gravimetric method (Figure 3). Therefore, it can be said that the use of spectrophotometric method as reference analysis in NIR calibrations for wax content can give more reliable results.

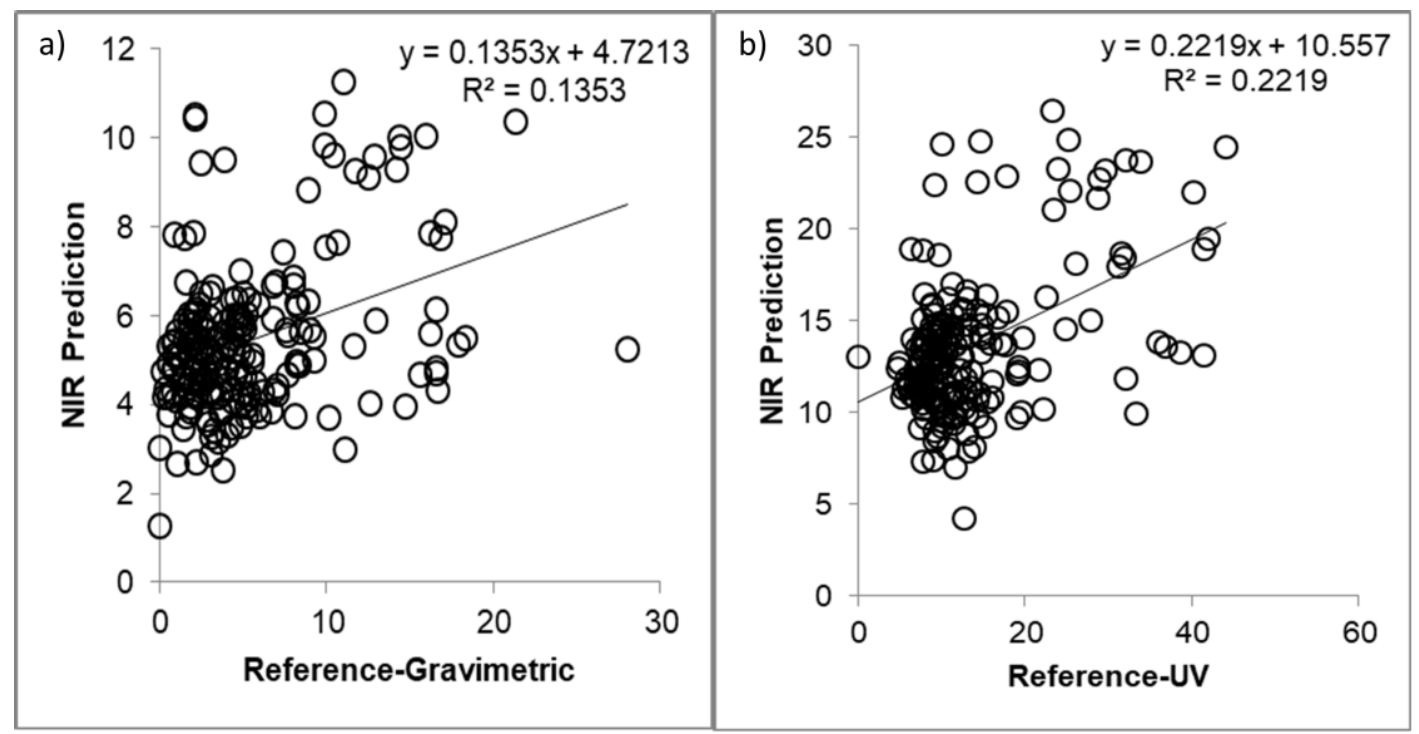

Figure 3 Relationship of NIR predictions with gravimetric (a) and UV-Vis spectroscopy (b) results for wax content.

\section{Conclusion}

The results of study showed that there was a remarkable difference between the reference methods in determining the content of surface wax in maize kernel. Spectrophotometric method had higher mean and range than gravimetric method. The correlation coefficient between the results of two methods was found as moderate. Undoubtedly, this caused variation in the performances of the calibration models in which the results from different methods were used as dependent variables. When we compared the generated models for prediction performance, we can say that UV-spectroscopic method provides higher prediction accuracy than the gravimetric method. Although UV-spectroscopic method had a higher prediction performance, our results indicate that it is difficult to determine the surface wax content by NIR spectroscopy. However, NIR spectroscopy may have a potential to be used in determining the content of wax in maize. We understand that the path followed in this study was not the most efficient way for the development of NIR calibration to predict surface wax content in maize kernel. Different approaches may enhance the results. It may be argued that a method that allows the collection of spectral data from a single intact seed can significantly improve the efficacy of the calibration models to estimate the wax content of maize kernel.

\section{References}

Lawrence, S. et al. (2001). Persistence of Web References in Scientific Research. Computer. 34, 2631. doi:10.1109/2.901164, http://dx.doi.org/10.1109/2.901164

Smith, Joe, (1999), One of Volvo's core values. [Online] Available: http://www.volvo.com/environment/index.htm (July 7, 1999)

Strunk, W., Jr., \& White, E. B. (1979). The elements of style. (3rd ed.). New York: Macmillan, (Chapter 4).

Van der Geer, J., Hanraads, J. A. J., \& Lupton R. A. (2000). The art of writing a scientific article. Journal of Scientific Communications, 163, 51-59

$90 \mid \mathrm{P}$ a g e

www.iiste.org 
Asperger, A., Engewald, W. \& Fabian, G. (2001). Thermally assisted hydrolysis and methylation-a simple and rapid online derivatization method for the gas chromatographic analysis of natural waxes. J Anal Appl Pyrol, 61, 91-109.

Baye, T.M., Pearson, T.C \& Mark Settles, A. (2006). Development of a calibration to predict maize seed composition using single kernel near infrared spectroscopy. Journal of Cereal Science, 43, $236-243$

Bianchi, G., Avato, P. \& Salamini F. (1984). Surface Waxes from Grain, Leaves, and Husks of Maize (Zea mays L.). Cereal Chemistry, 61,45-47.

Bragdon, J. (1951). Colorimetric determination of blood lipids. J. Biol. Chem, 190, 513-517.

Brown, R.L. et al. (1999). Advances in the Development of Host Resistance in Corn to Aflatoxin Contamination by Aspergillus flavus. Southern Regional Research Center, USDA-ARS, New Orleans, LA 70179 89:(2), 113-117.

Brown, R. L. et al. (2001). Resistance to Aflatoxin Accumulation in Kernels of Maize Inbreds Selected for Ear Rot Resistance in West and Central Africa. Journal of Food Protection, 64(3), 396-400.

Sampietro, D.A. et al. (2009). The pericarp and its surface wax layer in maize kernels as resistance factors to fumonisin accumulation by Fusarium verticillioides. Crop Protection Volume 28, Issue 2. $196-200$.

Dar Z.A., et al. (2017). Variability in epicuticular wax content among temperate maize lines as a drought tolerance related mechanism, Int. J. Curr. Microbiol. App. Sci., 6 : 441-445.

Ebercon, A., Blum, A. \& Jordan, W. R. 1977. A rapid colorimetric method for epicuticular wax content of sorghum leaves. Reprinted from Crop Science, 17,179-180.

Egesel, C.Ö. \& Kahriman, F. (2012). Determination Of Quality Parameters In Maize By Nir Reflectance Spectroscopy. Journal of Agricultural Sciences, 18,43-53.

Egesel, C.Ö., et al. (2016). Analysis of Fatty Acids in Kernel, Flour and Oil Samples of Maize by NIR Spectroscopy using Conventional Regression Methods, Cereal Chemistry, 93: 487-492.

Egesel, C.Ö., et al. (2015). Mısırda protein ve yağ oranının FT-NIR (Fourier Dönüşümlü Yakın Kızıl Ötesi Yansıma) spektroskopisi yöntemi ile tespitinde örnek tipi ve kemometrik metodun etkisi, Süleyman Demirel Üniversitesi Ziraat Fakültesi Dergisi, 10, 51-61.

Gembeh, S. V., et al. (2001). Identification of chemical components of corn kernel pericarp wax associated with resistance to Aspergillus flavus Infection and Aflatoxin Production. J. Agric. Food Chem., 49, 4635-4641.

Grob, K, et al. (1994). Recognition of adulterated oils by direct analysis of the minor components. Eur J Lipid Sci Tech., 96, 286-290.

Guo, B. Z. et al. (1995). Wax and cutin layers in maize kernels associated with resistance to aflatoxin production by Aspergillus flavus. Journal of Food Protection, 58(3), 296-300.

Hatfield, J. L. et al. (2008). Chapter 2: Agriculture, in "The Effects of Climate Change on Agriculture, Land Resources, Water Resources, and Biodiversity". Edited by Margeret Walsh. U.S. Climate Change Science Program Synthesis and Assessment Product 4.3

Kahriman F. et al. (2015). Mısırda karotenoid içeriğinin NIRs (Yakın Kızıl Ötesi Spektroskopisi) ile tespiti, 11. Tarla Bitkileri Kongresi, Çanakkale, Türkiye, 7-10 Eylül 2015, ss.252-252 
Kahriman F., et al., 2017. Efficiency of different chemometric methods for determination of oil content in maize by NIR spectroscopy, AGROSYM 2017, Jahorina, 5-8 October 2017, Bosnia and Herzegovina, pp.788-793.

Kunst, L., \& Samuels L., 2009. Plant cuticles shine: advances in wax biosynthesis and export. Current Opinion in Plant Biology 12(6):721-727.

Osborne, B. G. (2000). Near-infrared spectroscopy in food analysis. Pages 4069-4081 in: Encyclopedia of Analytical Chemistry. R. A. Meyers, ed. Wiley: Hoboken, NJ.

Prieto N, et al. (2017). A review of the principles and applications of near-infrared spectroscopy to characterize meat, fat, and meat products, Appl. Spectrosc., 71, 1403-1426

Sharma, P. et al. (2018). Properties, variations, roles, and potential applications of epicuticular wax: a review, Turkish Journal of Botany, 42, 135-149.

Regert, M, Langlois, J. \& Colinart, S. (2005). Characterisation of wax works of art by gas chromatographic procedures. J Chromatogr A, 1091,124-136.

Russin, J.S. et al. (1997). Comparison of kernel wax from corn genotypes resistant or susceptible to aspergillus flavus, Phytopatology, 87(5), 529-533.

Tubajika, K. M. \& Damann K. E. (2001). Sources of resistance to aflatoxin production in maize. $J$. Agric. Food Chem. 49, 2652-2656.

Vanhercke, T, C. C. et al. (2013). Metabolic engineering of plant oils and waxes for use as industrial feedstocks. Plant Biotechnology Journal, 11,197-210. 